\title{
Brand Engagement in Self-Concept: Scale Properties and the Global Nature of the Construct
}

\author{
Wiktor Razmus ${ }^{1} \cdot$ Mariola Laguna $^{1}$ \\ Published online: 23 March 2017 \\ (C) The Author(s) 2017. This article is published with open access at Springerlink.com
}

\begin{abstract}
The aim of the two presented studies was to attest whether the brand engagement in self-concept (BESC) has a global nature and to further evaluate the psychometric properties of the BESC Scale. In the first study $(N=997)$, we tested the psychometric properties of the Polish version of the BESC Scale and confirmed its factorial structure using confirmatory factor analysis. The BESC scale has good internal consistency $(\alpha=.95)$, construct validity, and demonstrate full scalar invariance across gender. The second study $(N=287)$ provided evidence that BESC has a global nature and that it is significantly related to the assessment of self-brand distance for brands that belong to various product categories and are important to consumers. Overall, current results provide psychometric support for the BESC Scale as an appropriate measure of global propensity to include important brands as part of the self-concept.
\end{abstract}

Keywords Brand engagement in self-concept · Self . Consumption · Psychological assessment $\cdot$ Measurement invariance

\section{Introduction}

In the last few years, we have been witnessing a growth of interest in engagement issues in psychology marketing

Wiktor Razmus

wrazmus@gmail.com

Mariola Laguna

laguna@kul.pl

1 Institute of Psychology, The John Paul II Catholic University of Lublin, Al. Raclawickie 14, 20-950 Lublin, Poland
(Brodie et al. 2011; Hollebeek 2011a; Vivek et al. 2012). Apart from purely theoretical analyses, research is conducted in two directions: (1) analyzing the determinants of various forms of customer/consumer engagement and its consequences (Albert et al. 2013; Belaid and Behi 2011; Carroll and Ahuvia 2006; Kim et al. 2014; Lam et al. 2013; Razmus et al. 2017; Stokburger-Sauer et al. 2012) and (2) developing instruments measuring various forms of customer/consumer engagement (Escalas 2004; Escalas and Bettman 2005; Vivek et al. 2014; Whan Park et al. 2010). Among the instruments developed, constituting operationalizations of new theoretical construct, what deserves attention is the approach to analyzing brand engagement in self-concept (BESC). The authors of this conception define BESC as a global (i.e., independent of product category) propensity to include important brands as part of the self-concept (Sprott et al. 2009). The novelty of this construct as compared to previous ones lies in the fact that it does not focus on relations with specific brands but on the predisposition to include important brands in the self-concept.

Preliminary research using the BESC Scale in U.S. culture indicate good psychometric properties of the scale (Flynn et al. 2011; Sprott et al. 2009). It is important to investigate if the scale is suitable for use in Poland by testing it psychometric properties. A limitation of the existing studies is the lack of empirical evidence confirming the main assumption of the conception regarding the global nature of this construct. The authors assumed that including important brands in the self-concept does not depend on product category and that individuals may construct their self-concept using brands from different product categories (consumed in public or in private). This thesis has not been empirically confirmed so far.

Our research fills those gaps. In the first study, we analyze the psychometric properties of the Polish version of the BESC Scale - namely, we test its construct validity and its measurement invariance across gender. In the second study, we test the 
global character of the BESC construct. Both studies were carried out in Poland, which makes it possible to test the universality of the concept developed in the U.S. in a different, European cultural context.

\section{Brand Engagement in Self-Concept}

For a long time, the key concepts for marketing practitioners and theorists have been the quality of products and services and consumer satisfaction (Taylor and Baker 1994). It was assumed that a high level of consumer satisfaction leads to an increase in consumer loyalty. With time, however, it turned out that the measurement of satisfaction does not make it possible to predict whether what is the case is inertia repeat purchase or actual loyalty (Amine 1998). Researchers have proposed to fill this gap by focusing on customer/consumer engagement (Bowden 2009). For a few years this has been probably the most dynamically developing perspective in the field of customer management (Verhoef et al. 2010).

"Engagement" issues has been analyzed in many scientific disciplines: sociology, management, political sciences, psychology education, and organizational psychology (Brodie et al. 2011; Hollebeek 2011a; Vivek et al. 2012). Yet, until 2005 , very few articles raised the question of "consumer engagement," "customer engagement," or "brand engagement" (Brodie et al. 2011). And even though the increase in the number of research papers addressing these issues was not observed until after 2010, interest in customer/ consumer engagement was already developing in several fundamental perspectives (Brodie et al. 2011; Hollebeek 2011a; Vivek et al. 2012). On the one hand, researchers stress that in the contemporary market customer engagement is an element necessary for generating company efficiency (Brodie et al. 2011), on the other hand, they stress the need to focus on behaviors that go beyond transactions (van Doorn et al. 2010; Verhoef et al. 2010; Vivek et al. 2012). Thus, consumer engagement does not consist only in engaging in the purchase of a product. One of the types of engagement that we wish to focus on is consumer brand engagement.

In the literature, the issues of consumer brand engagement (not consumer engagement in general) is analyzed in accordance with two approaches. The first approach focuses on brand identification. Researchers analyze the degree of including the brand as part of the self-concept - self-brand connections (Escalas 2004; Escalas and Bettman 2003), the strength of the bond between the brand and the self - brand attachment (Whan Park et al. 2010), and the extent to which identity is filled with brand meanings - consumer-brand identification (Stokburger-Sauer et al. 2012). The common feature of these theoretical proposals is the reduction of engagement to an aspect of brand identification. In the second approach, customer/consumer brand engagement is analyzed more comprehensively. Customer brand engagement is treated as "the level of an individual customer's motivational, brandrelated and context-dependent state of mind characterised by specific levels of cognitive, emotional and behavioural activity in direct brand interactions" (Hollebeek 2011b, p. 790). Few studies on these construct treat brand identification as a consequence rather than element of engagement. Such an understanding of consumer brand engagement is certainly interesting, but it still remains in the early stages of analyses (Hollebeek 2011a, 2011b; Hollebeek and Chen 2014) and in the phase of first attempts at developing a measurement instrument (Hollebeek et al. 2014). The construct of BESC, proposed by Sprott's team (2009), represents the first approach to analyzing consumer brand engagement. This construct is distinguished among the proposals of other researchers (Escalas 2004; Escalas and Bettman 2003; Stokburger-Sauer et al. 2012; Whan Park et al. 2010) by the approach adopted in its conceptualization and measurement. BESC is understood as a global propensity to include important brands as part of one's self-concept (Sprott et al. 2009). The theoretical background of this idea is the cognitive schema theory, in which the self is understood as a set of schemas representing a stable structure of knowledge (Markus 1977). The research conducted by Sprott's team (2009) showed that BESC is useful in the field of marketing because it meaningfully affects brand-related consumer constructs.

The original BESC Scale developed by Sprott and colleagues (2009) is a one-dimensional measure characterized by high internal consistency in various groups distinguished according to age, gender, income, and education (Flynn et al. 2011). The scale consists of eight items (e.g., "I have a special bond with the brands that I like," "Part of me is defined by important brands in my life") and the rating is done on a 7point Likert scale (1 - strongly disagree, 7 - strongly agree). Possible results range between 1 and 7 and are computed as arithmetical means of ratings of all the items. The higher the score, the higher is the propensity to include important brands in the self-concept. The scale has been used in different countries and consumption context (Bitter et al. 2014; Goldsmith et al. 2014; Pentina et al. 2013). These results suggest that the BESC scale not only constitutes a useful way of measuring brand engagement in self-concept, but that the construct has important implications for consumer behavior research. We therefore decided to test and validate the Polish version of the BESC scale in order to check it psychometric properties.

Sprott and colleagues (2009) claim that BESC is a global tendency, which means it does not depend on product category. Individuals may construe their self-concept by engaging the brands of products consumed in public or in private (distinction proposed by Hoyer and MacInnis (2008). This global approach, instead of focusing on specific self-brand connections, is the novelty that Sprott's team promotes. Defining $\mathrm{BESC}$ without reference to specific brands gives this construct 
a highly abstract character, which some may regard as controversial. Resolving the issue of the general nature of the BESC construct requires conducting additional research, since the authors of this concept did not provide any evidence supporting their thesis. It is worth testing empirically whether consumers include all product brands in their self-concept or only specific ones - for example, those consumed in public.

\section{Study 1. The Psychometric Properties of the Polish Version of the BESC Scale}

The aim of this study was to test the psychometric properties of the BESC Scale: its construct validity, reliability, and measurement invariance across gender in a Polish sample. In order to enable the generalization of results, the study was conducted on a large and diverse sample of consumers.

\section{Method}

Participants and Procedure The study was carried out using the survey method, on a sample of 997 consumers from Poland (499 women) aged $18-81$ years $(M=36.73$, $S D=13.07)$. The participants were contacted by researchers and filled in paper-and-pencil questionnaires. Participation in the study was voluntary and unremunerated. The anonymity and confidentiality of data was ensured. Informed consent was obtained from all individual participants included in the study.

Measures The Polish adaptation of the BESC Scale was used (Razmus 2012).

\section{Results and Discussion}

Descriptive Statistics The mean BESC score for the whole sample is $3.05(S D=1.42)$, indicating a moderate and varied intensity of BESC. The scores show a right-skewed distribution, i.e., a majority of scores are below the mean (the Kolmogorov-Smirnov test with Lilliefors correction $Z=.10$; $p<.001$, skewness $=0.47$ ). Cronbach's $\alpha$ reliability of the scale in this study is .95 , which is high.

Confirmatory Factor Analysis The scale's construct validity was verified through an analysis of its factor structure. In order to determine the internal structure of the scale, we performed a confirmatory factor analysis (CFA; Brown 2006) with ML estimation, using Amos 21 (Arbuckle 2005). To assess model fit, we used the $c h i^{2}$ Goodness-of-Fit Statistic, the Root Mean Square Error of Approximation (RMSEA), the Standardized Root Mean Square Residual (SRMR), and the Comparative Fit Index (CFI). RMSEA and SRMS values below .08, and
CFI values higher than .90 indicate an acceptable model fit (Brown 2006). To test differences between models, we calculated the $c h i^{2}$ difference tests $\left(\Delta c h i^{2}\right)$ and difference in CFI $(\triangle \mathrm{CFI})$, which, if higher than .01, indicates a significant difference in model fit (Brown 2006).

Two subsequent models were tested. Model 1 assumed that the scale's items made up single factor and that measurement errors of individual items were not correlated. This model does not fully fit the data well $\left(c h i^{2}=149.394, d f=20\right.$, $p<.001$, RMSEA $=.081$, SRMR $=.067$, CFI $=.853$ ). Model 2 allowed the correlation of measurement errors between item 1 and item 2 and between item 7 and item 8 . This model turned out to fit the data well $\left(c h i^{2}=87.740, d f\right.$ $=18, p<.001, \mathrm{RMSEA}=.062, \mathrm{SRMR}=.041, \mathrm{CFI}=.921)$ and significantly better than Model $1\left(\Delta c h i^{2}=61.654\right.$, $\Delta d f=2, p<.001, \Delta \mathrm{CFI}=.068)$. Model 2 was accepted as the best representation of BESC construct.

Gender Invariance For testing measurement invariance, in a first step Model 2 was fitted to the data from each group (men and women) separately. Then, in a second step, a series of increasingly restricted models were tested using multigroup confirmatory factor analysis (MGCFA). The first model (configural invariance) allowed to test whether the structure of BESC Scale is the same in samples men and women. In the second model (metric invariance), all factor loadings were constrained to be equal across gender. In the third model (scalar invariance), we added equivalent intercepts constrain across samples (Meredith 1993). The increasingly restricted models were compared using $\Delta \mathrm{CFI}$ test. An absolute difference in CFI that is less than .01 would indicate measurement invariance (Cheung and Rensvold 2002).

In a first step, a single-factor CFA model of BESC was tested separately in each samples. The model showed a good fit in the samples of men $\left(c h i^{2}=88.162, d f=18, p<.001\right.$, RMSEA $=.089, \mathrm{SRMR}=.022, \mathrm{CFI}=.980)$ and women $\left(c h i^{2-}\right.$ $=123.775, d f=18, p<.001, \mathrm{RMSEA}=.109, \mathrm{SRMR}=.024$, CFI $=.973$ ), except for RMSEA. In a second step, we used MGCFA to examine measurement invariance across gender. As shown in Table 1, the configural model fits to the data well, indicating that configural invariance was achieved. Equality constraints were then imposed on all factor loadings across both groups. As model comparison shows, the $\Delta \mathrm{CFI}=.001$ indicated full metric invariance. Next, equality constraints were imposed on all item intercepts to test scalar invariance. An absolute difference in CFI supported full scalar invariance across gender.

The Mann-Whitney test showed that there are no differences between men and women in mean BESC scores $(U=121,144.50, p<.529)$.

Summing up, the study confirms the one-factor structure and high reliability of the BESC Scale in the Polish sample. This is consistent with the results obtained by Sprott and 
Table 1 Measurement invariance of BESC Scale across gender

\begin{tabular}{|c|c|c|c|c|c|c|c|c|c|c|c|}
\hline Modele & $x^{2}$ & $d f$ & $p$ & RMSEA & SRMR & CFI & Model comparison & $\Delta \chi^{2}$ & $\Delta d f$ & $p$ & $\Delta \mathrm{CFI}$ \\
\hline M1. Configural invariance & 211.937 & 36 & .001 & .070 & .022 & .977 & - & & & & - \\
\hline M2. Metric invariance & 216.481 & 43 & .001 & .064 & .022 & .977 & M2 vs M1 & 4.545 & 7 & .715 & .001 \\
\hline M3. Scalar invariance & 224.295 & 50 & .001 & .059 & .022 & .977 & M3 vs M2 & 7.814 & 7 & .349 & .001 \\
\hline
\end{tabular}

$\chi^{2}=$ chi-square; $d f=$ degrees of freedom; RMSEA, Root Mean Square Error of Approximation; SRMR, Standardized Root Mean Square Residual; CFI, Comparative Fit Index; $\Delta \chi^{2}$, chi-square difference; $\Delta d f=$ degrees of freedom difference; $\Delta C F I$, Comparative Fit Index difference

colleagues (2009) on a U.S. sample and further validates the scale. It can be used for the reliable measurement of one of the important conceptualizations of consumer engagement (Bowden 2009). The BESC Scale was found to be equivalent in samples of men and women, demonstrating full scalar invariance, which allow meaningful comparisons of mean scores between these samples (Meredith 1993).

\section{Study 2. Brand Engagement in Self-Concept as a Global Propensity}

The innovative character of the conception proposed by Sprott's team (2009) consists in abandoning the analysis of relations between the self-concept and specific brands in favor of a more general approach. BESC assumes that individuals may, to different degrees, include important brands from various product categories as part of their self-concept. Thus presented, the proposal requires empirical support.

Based on the theoretical reflections, the following research questions will be answered in this study:

Research Question 1: Does the tendency for brand engagement in self-concept involve including important brands of various product categories in the self-concept? Research Question 2: Are there differences in the strength of the connection of BESC with the inclusion of important brands as part of the self-concept between the categories of products consumed in public and products consumed in private?

\section{Method}

Measures and Preliminary Study To measure the extent to which important brands from different product categories are included in the self-concept, we used the estimation of selfbrand distances on a 7-point scale, from 0 - the brand is very close to myself to 6 - the brand is outside myself. When reading the names of each of the 20 product categories, the participants were supposed to think of the brand representing a particular category that they preferred the most, write down its name, and indicate how far it was from the self.
In selecting product categories for the study, we took into account (1) the importance of brand in product categories (the product categories selected were those in which brand made a considerable difference to consumers) and (2) the distinction between products generally consumed in public and those generally consumed in private. Data concerning brand importance in each product category come from individual interviews conducted with 101 consumers (49.5\% women) representing various age groups $(M=39.73, S D=15.92)$. In the study we used 10 products generally meant for public use and 10 products generally intended for private use (Table 2).

We also administered the Polish adaptation of the BESC Scale (Razmus 2012). Its Cronbach's $\alpha$ reliability in this study was 92 .

Participants and Procedure The study was carried out on a sample of 287 individuals from Poland (150 women) aged 19-69 years $(M=27.75, S D=9.40)$. Data was gathered using paper-and-pencil questionnaires during direct contact with the respondents. Participation in the study was voluntary and the participants did not receive any reward. The anonymity and confidentiality of data was ensured. Informed consent was obtained from all individual participants included in the study.

\section{Results and Discussion}

Descriptive Statistics Table 2 presents mean self-brand distances for brands important to respondents and representing different products categories. The closer the values are to 0 , the closer the brands from particular product categories are to the self. Mean self-brand distances are below 3.84 on a scale from 0 to 6 . The greatest diversity in the participants' responses was found for brands of products such as beer, vodka, watches, or cigarettes $(S D>2)$. Mean BESC score is 3.31 $(S D=1.21)$, which means it is close to the middle of the rating scale and indicates a moderate and at the same time varied intensity of BESC in the whole sample. The brands rated as the closest to the self are brands of perfume, mobile phones, cars, and computer equipment.

In order to check whether BESC involves the inclusion of important brands from different product categories as part of the self-concept, we computed Person's $r$ correlations between 
Table 2 Mean self-brand distances for brands representing different products categories and correlations between BESC and self-brand distances

\begin{tabular}{|c|c|c|c|c|}
\hline \multirow[t]{2}{*}{ Product } & \multirow[t]{2}{*}{$N$} & \multicolumn{2}{|c|}{ Self-brand distance } & \multirow[t]{2}{*}{ Correlation with BESC } \\
\hline & & $M$ & $S D$ & \\
\hline $\operatorname{Cars}^{\mathrm{a}}$ & 262 & 2.67 & 1.93 & $-.29 * *$ \\
\hline RTV equipment $^{\mathrm{b}}$ & 246 & 3.30 & 1.83 & $-.40 * *$ \\
\hline Cell phones ${ }^{\mathrm{a}}$ & 279 & 2.52 & 1.83 & $-.36 * *$ \\
\hline Household appliances ${ }^{\mathrm{b}}$ & 230 & 3.62 & 1.83 & $-.44 * *$ \\
\hline Computer products $^{\mathrm{a}}$ & 260 & 2.76 & 1.91 & $-.36 * *$ \\
\hline Coffee $^{b}$ & 236 & 3.12 & 1.93 & $-.32 * *$ \\
\hline Cameras $^{\mathrm{a}}$ & 240 & 3.38 & 1.86 & $-.33 * *$ \\
\hline Cosmetics $^{\mathrm{b}}$ & 251 & 2.62 & 1.81 & $-.38 * *$ \\
\hline Beer $^{\mathrm{a}}$ & 255 & 2.86 & 2.00 & $-.24 * *$ \\
\hline Perfumes ${ }^{b}$ & 243 & 2.36 & 1.84 & $-.38 * *$ \\
\hline Shoes $^{\mathrm{a}}$ & 236 & 2.82 & 1.75 & $-.31 * *$ \\
\hline Chocolates $^{\mathrm{b}}$ & 257 & 2.72 & 1.91 & $-.28 * *$ \\
\hline Vodka $^{\mathrm{a}}$ & 233 & 3.43 & 2.05 & $-.17 * *$ \\
\hline $\mathrm{Tea}^{\mathrm{b}}$ & 247 & 2.99 & 1.82 & $-.27 * *$ \\
\hline Sportswear $^{\mathrm{a}}$ & 230 & 3.08 & 1.81 & $-.37 * *$ \\
\hline Painkillers ${ }^{\mathrm{b}}$ & 227 & 3.49 & 1.90 & $-.29 * *$ \\
\hline Watches $^{\mathrm{a}}$ & 200 & 3.54 & 2.02 & $-.30 * *$ \\
\hline Newspapers ${ }^{\mathrm{b}}$ & 212 & 3.35 & 1.91 & $-.31 * *$ \\
\hline Cigarettes $^{\mathrm{a}}$ & 178 & 3.84 & 2.30 & $-.27 * *$ \\
\hline Juices $^{\mathrm{b}}$ & 237 & 3.06 & 1.76 & $-.28 * *$ \\
\hline
\end{tabular}

$N=$ number of ratings for each product category

${ }^{\mathrm{a}}$ publicly consumed product; ${ }^{\mathrm{b}}$ privately consumed product

$* * p<.01$
BESC and self-brand distances for used and preferred brands from 20 product categories (Table 2). Statistically significant correlations were found for all the 20 product categories analyzed. The values of the correlations range from -.44 for household appliances to -.17 for vodka brands. These results show that BESC involves the inclusion of the respondents' important brands from different product categories - the higher the level of BESC, the closer to the self these brands are rated to be. The weakest correlation was found in the case of the "vodka" category.

A Multilevel Analysis Because each participant assessed self-brand distances for important brands representing 20 product categories, the obtained data have a two-level structure: the assessments of self-brand distances for various product brands (level 1) belong to a particular person (level 2); using the terminology of multilevel analysis - lower level data are nested in the higher level (Nezlek 2012). This allows to apply hierarchical linear modeling (HLM; Raudenbush et al. 2011). Thanks to this method, it becomes possible to determine, using one index for all product categories, whether $\mathrm{BESC}$ is related to self-brand distances for important brands.
The tested relationship is expressed by the following twolevel regression equation:

$$
\operatorname{DISTANCE}_{j i}=\beta_{00}+\beta_{01}{ }^{*} \mathrm{BESC}_{i}+r_{0 i}+e_{j i}
$$

where DISTANCE $E_{t i}$ is the dependent variable (self-brand distance) for person $i$ evaluating brand $j$ (i.e., level 1 variable); $\beta_{01}$ is the regression coefficient representing the relationship between the dependent variable and the level of BESC for person $i$ (i.e., predictor from level 2), and $r_{O i}$ and $e_{j i}$ represent random error terms (for each level). The measure of BESC was entered into the equation as grand mean centered, and the coefficients were tested as random (Nezlek 2012).

The results of HLM analysis show that with an increase of BESC by one unit on the measurement scale, self-brand distances for important brands decrease by .47 of a unit; and this regression coefficient is statistically significant at $p<.001$. This suggests that the tendency for brand engagement in self-concept is significantly related to the assessment of selfbrand distance for various product brands.

In order to check if the strength of the relationship between BESC and self-brand distance for important brands differs 
between brands consumed in public and ones consumed in private, mean self-brand distances were computed for both these categories of products. Pearson's $r$ correlation coefficient between BESC and mean self-brand distance for important brands is $r=-.46(p<.01)$ in the case of products consumed in public and $r=-.52(p<.01)$ in the case of products consumed in private. The difference between these two correlation coefficients turned out not to be statistically significant $(p<.346)$. This indicates that the strength of the relationship between BESC and the inclusion of important brands in the self-concept is similar for brands of products consumed in private and in public.

Summing up, the results of the study confirm the global character of BESC, which was postulated in theory (Sprott et al. 2009). The tendency to include important brands in the self-concept applies to the same extent to brands from different product categories. This pattern is confirmed both in analyses concerning particular product categories and in the multilevel analysis.

\section{General Discussion}

The aim of the research was to analyze the psychometric properties of the Polish version of the BESC Scale namely, to test its construct validity and measurement invariance across gender as well as to test the global character of the construct. The first study shows that the scale for measuring BESC has good psychometric properties. It is highly reliable and its construct validity was confirmed on the basis of confirmatory factor analysis showing that the scale indeed measures a single latent factor. We have also confirmed that scales' scores demonstrate full scalar invariance across gender. Construct equivalence represents a prerequisite for unambiguously interpreting differences in mean scores (Meredith 1993).

The second study confirmed that BESC may be treated as a global construct - the assessment of self-brand distances for important brands was found to be related to BESC for all the product categories. The 20 product categories used in the present research can be regarded as a representative spectrum of stimuli, enabling a greater objective generalization of the results. The weakest correlation was found in the case of the "vodka" category. Perhaps this figure is slightly underestimated because describing a vodka brand as close to the self could present a person in an unfavorable light. The study also provided evidence that brand-extended self-construal involves including both types of brands as part of the selfconcept to an equal degree: brands of products consumed in public and ones consumed in private. The results of multilevel modeling, which is an approach more and more often used in analyses (Nezlek 2012), complement the analyses of correlations performed for each product category and confirm that an increase in the level of BESC involves treating important brands from various product categories as closer to the self.

Based on the current findings, it can be said that the construct proposed by Sprott's team (2009) does have a global nature indeed. A person's empirical self (James 1920; Mittal 2006) can be extended to include various objects marked with a brand. This study thus brought an empirical verification of one of the assumptions of BESC (Sprott et al. 2009), which had been only theoretically postulated before. It therefore becomes legitimate to speak of a personality-related tendency to include important brands in the self-concept - a tendency that applies to various product categories. This facilitates conducting broader nomothetic analyses, not focused on a particular brand.

\section{Conclusions and Limitations}

The operationalization of consumer brand engagement proposed by Sprott's team (2009) is one of several operationalizations of various forms of brand engagement described in the literature (Escalas 2004; Escalas and Bettman 2003; Stokburger-Sauer et al. 2012; Whan Park et al. 2010). Its originality consists in measuring global propensity to include important brands as part of the self-concept. The presented research provides strong arguments in favor of the good psychometric properties of the BESC Scale, namely construct validity, measurement reliability, measurement invariance across gender and the possibility of adequately measuring the global propensity to include important brands as part of the self-concept.

What constitutes a limitation of the conception of BESC is the fact that it focuses exclusively on consumer brand engagement through the lens of identification with the brand. Other researchers propose multidimensional approaches to consumer brand engagement (Hollebeek 2011a, 2011b; Hollebeek and Chen 2014; Hollebeek et al. 2014). This suggests that perhaps also with regard to BESC it is possible to seek other dimensions of brand engagement in self-concept, apart from the one that is measured using the BESC Scale, for example emotional and behavioral activities in brand interactions. Presented studies are not free from some other limitations. Firstly, the sample in the second study was relatively small, however, it consisted of agediverse individuals from various regions of Poland. Secondly, measurement of self-brand distances (Study 2) was performed using a single item. In the future studies further investigation of the psychometric properties of the BESC Scale is needed. One of the possible research directions is also testing for measurement invariance across cultures.

Compliance with Ethical Standards All procedures performed in studies involving human participants were in accordance with the ethical standards of the institutional and/or national research committee and with the 1964 Helsinki declaration and its later amendments or comparable ethical standards. 
Conflict of Interest Wiktor Razmus declares that he has no conflict of interest.

Mariola Laguna declares that she has no conflict of interest.

Financial support This paper was partly supported by the NCN DEC2011/01/B/HS4/05178.

Open Access This article is distributed under the terms of the Creative Commons Attribution 4.0 International License (http:// creativecommons.org/licenses/by/4.0/), which permits unrestricted use, distribution, and reproduction in any medium, provided you give appropriate credit to the original author(s) and the source, provide a link to the Creative Commons license, and indicate if changes were made.

\section{References}

Albert, N., Merunka, D., \& Valette-Florence, P. (2013). Brand passion: Antecedents and consequences. Journal of Business Research, 66(7), 904-909.

Amine, A. (1998). Consumers' true brand loyalty: The central role of commitment. Journal of Strategic Marketing, 6(4), 305-319.

Arbuckle, J. (2005). Amos 6.0 User's Guide. Spring House: Amos Development Corporation.

Belaid, S., \& Behi, A. T. (2011). The role of attachment in building consumer-brand relationships: an empirical investigation in the utilitarian consumption context. Journal of Product \& Brand Management, 20(1), 37-47.

Bitter, S., Grabner-Kräuter, S., \& Breitenecker, R. J. (2014). Customer engagement behaviour in online social networks - the Facebook perspective. International Journal of Networking \& Virtual Organisations, 14(1/2), 197-220.

Bowden, J. L.-H. (2009). The process of customer engagement: A conceptual framework. Journal of Marketing Theory \& Practice, 17(1), 63-74.

Brodie, R. J., Hollebeek, L. D., Jurić, B., \& Ilić, A. (2011). Customer engagement: Conceptual domain, fundamental propositions, and implications for research. Journal of Service Research, 14(3), 252-271.

Brown, T. A. (2006). Confirmatory factor analysis for applied research. New York: Guilford Press.

Carroll, B., \& Ahuvia, A. (2006). Some antecedents and outcomes of brand love. Marketing Letters, 17(2), 79-89.

Cheung, G. W., \& Rensvold, R. B. (2002). Evaluating goodness-of-fit indexes for testing measurement invariance. Structural Equation Modeling, 9(2), 233-255.

Escalas, J. E. (2004). Narrative processing: Building consumer connections to brands. Journal of Consumer Psychology, 14(1-2), 168-180.

Escalas, J. E., \& Bettman, J. R. (2003). You are what they eat: The influence of reference groups on consumers' connections to brands. Journal of Consumer Psychology, 13(3), 339.

Escalas, J. E., \& Bettman, J. R. (2005). Self-construal, reference groups, and brand meaning. Journal of Consumer Research, 32(3), 378-389.

Flynn, L. R., Goldsmith, R. E., \& Korzenny, F. (2011). Brand engagement in self-concept: A psychometric and demographic analysis. Journal of Multidisciplinary Research, 3(2), 5-18.

Goldsmith, R. E., Reinecke Flynn, L., \& Clark, R. A. (2014). The etiology of the frugal consumer. Journal of Retailing \& Consumer Services, 21(2), 175-184.

Hollebeek, L. (2011a). Exploring customer brand engagement: Definition and themes. Journal of Strategic Marketing, 19(7), 555-573.

Hollebeek, L. (2011b). Demystifying customer brand engagement: Exploring the loyalty nexus. Journal of Marketing Management, 27(7/8), 785-807.
Hollebeek, L., \& Chen, T. (2014). Exploring positively- versus negatively-valenced brand engagement: A conceptual model. Journal of Product \& Brand Management, 23(1), 62-74.

Hollebeek, L., Glynn, M. S., \& Brodie, R. J. (2014). Consumer brand engagement in social media: Conceptualization, scale development and validation. Journal of Interactive Marketing, 28(2), 149-165.

Hoyer, W. D., \& MacInnis, D. J. (2008). Consumer behavior (5th ed.). Mason: Cengage Learning.

James, W. (1920). Psychology: Briefer course. New York: Henry Holt \& Company.

Kim, K., Park, J., \& Kim, J. (2014). Consumer-brand relationship quality: when and how it helps brand extensions. Journal of Business Research, 67(4), 591-597.

Lam, S., Ahearne, M., Mullins, R., Hayati, B., \& Schillewaert, N. (2013). Exploring the dynamics of antecedents to consumer-brand identification with a new brand. Journal of the Academy of Marketing Science, 41(2), 234-252.

Markus, H. (1977). Self-schemata and processing information about the self. Journal of Personality and Social Psychology, 35(2), 63-78.

Meredith, W. (1993). Measurement invariance, factor analysis and factorial invariance. Psychometrika, 58(4), 525-543.

Mittal, B. (2006). I, me, and mine-how products become consumers' extended selves. Journal of Consumer Behaviour, 5(6), 550-562.

Nezlek, J. B. (2012). Multilevel modeling for psychologists. In H. Cooper, P. M. Camic, D. L. Long, A. T. Panter, D. Rindskopf, \& K. J. Sher (Eds.), APA handbook of research methods in psychology, Vol 3: Data analysis and research publication (pp. 219-241). Washington, DC: American Psychological Association.

Pentina, I., Gammoh, B. S., Zhang, L., \& Mallin, M. (2013). Drivers and outcomes of brand relationship quality in the context of online social networks. International Journal of Electronic Commerce, 17(3), 63-86.

Raudenbush, S. W., Bryk, A. S., Cheong, Y. F., Congdon, R. T., \& du Toit, M. (2011). HLM7: Hierarchical linear and nonlinear modeling. Chicago: Scientific Software International.

Razmus, W. (2012). Skala Konstruowania Siebie przez Marki (KSM): Polska adaptacja skali Brand Engagement in Self-Concept (BESC). Marketing i Rynek, 8, 15-19.

Razmus, W., Jaroszyńska, M., \& Palęga, M. (2017). Personal aspirations and brand engagement in self-concept. Personality and Individual Differences, 105, 294-299.

Sprott, D., Czellar, S., \& Spangenberg, E. (2009). The importance of a general measure of brand engagement on market behavior: Development and validation of a scale. Journal of Marketing Research, 46(1), 92-104.

Stokburger-Sauer, N., Ratneshwar, S., \& Sen, S. (2012). Drivers of consumer-brand identification. International Journal of Research in Marketing, 29(4), 406-418.

Taylor, S. A., \& Baker, T. L. (1994). An assessment of the relationship between service quality and customer satisfaction in the formation of consumers' purchase intentions. Journal of Retailing, 70(2), 163-178.

van Doorn, J., Lemon, K. N., Mittal, V., Nass, S., Pick, D., Pirner, P., \& Verhoef, P. C. (2010). Customer engagement behavior: Theoretical foundations and research directions. Journal of Service Research, 13(3), 253-266.

Verhoef, P. C., Reinartz, W. J., \& Krafft, M. (2010). Customer engagement as a new perspective in customer management. Journal of Service Research, 13(3), 247-252.

Vivek, S. D., Beatty, S. E., Dalela, V., \& Morgan, R. M. (2014). A generalized multidimensional scale for measuring customer engagement. Journal of Marketing Theory \& Practice, 22(4), 401-420.

Vivek, S. D., Beatty, S. E., \& Morgan, R. M. (2012). Customer engagement: Exploring customer relationships beyond purchase. Journal of Marketing Theory \& Practice, 20(2), 122-146.

Whan Park, C., MacInnis, D. J., Priester, J., Eisingerich, A. B., \& Iacobucci, D. (2010). Brand attachment and brand attitude strength: Conceptual and empirical differentiation of two critical brand equity drivers. Journal of Marketing, 74(6), 1-17. 